\title{
REVIEW
}

\section{TSH suppressive therapy and bone}

\author{
Alessandro Brancatella ${ }^{1}$ and Claudio Marcocci ${ }^{2}$ \\ ${ }^{1}$ Endocrine Unit 1, Department of Clinical and Experimental Medicine, University of Pisa, Pisa, Italy \\ ${ }^{2}$ Endocrine Unit 2, Department of Clinical and Experimental Medicine, University of Pisa, Pisa, Italy \\ Correspondence should be addressed to C Marcocci: claudio.marcocci@med.unipi.it
}

\begin{abstract}
Thyroid hormones stimulate bone turnover in adults by increasing osteoclastic bone resorption. TSH suppressive therapy is usually applied in patients with differentiated thyroid cancer (DTC) to improve the disease outcome. Over the last decades several authors have closely monitored the potential harm suffered by the skeletal system. Several studies and meta-analyses have shown that chronic TSH suppressive therapy is safe in premenopausal women and men. Conversely, in postmenopausal women TSH suppressive therapy is associated with a decrease of bone mineral density, deterioration of bone architecture (quantitative CT, QCT; trabecular bone score, TBS), and, possibly, an increased risk of fractures. The TSH receptor is expressed in bone cells and the results of experimental studies in TSH receptor knockout mice and humans on whether low TSH levels, as opposed to solely high thyroid hormone levels, might contribute to bone loss in endogenous or exogenous thyrotoxicosis remain controversial. Recent guidelines on the use of TSH suppressive therapy in patients with DTC give value not only to its benefit on the outcome of the disease, but also to the risks associated with exogenous thyrotoxicosis, namely menopause, osteopenia or osteoporosis, age $>60$ years, and history of atrial fibrillation. Bone health (BMD and/or preferably TBS) should be evaluated in postmenopausal women under chronic TSH suppressive therapy or in those patients planning to be treated for several years. Antiresorptive therapy could also be considered in selected cases (increased risk of fracture or significant decline of BMD/TBS during therapy) to prevent bone loss.
\end{abstract}
Key Words
- thyroid cancer
- differentiated thyroid cancer
- levothyroxine
- bone mineral density
- trabecular bone score
- fractures

\section{Introduction}

Thyroid hormones are one of the most prescribed drugs in Western countries, mostly for the management of hypothyroidism either spontaneous or after thyroidectomy for benign diseases and differentiated thyroid cancer (DTC). The aim of treatment is to replace thyroid function but, in the latter condition, an additional aim is to keep the serum thyroid-stimulating hormone (TSH) at the lower limit of the normal range and possibly below (TSH suppressive therapy) to improve the outcome of the disease (see below). To obtain this biochemical endpoint supraphysiological doses of thyroid hormones are used and there is concern that this approach, particularly when chronically used, may increase the risk of adverse events, particularly for the cardiovascular system and in the skeleton $(1,2)$. In this review we will discuss the current indication of TSH suppressive therapy in patients with DTC, the potential adverse effects on bones and their prevention.

\section{Thyroid hormone and TSH actions in bone cells}

The maintenance of the adult skeletal structure and function requires a coordinated activity of bone-resorbing osteoclasts and bone-forming osteoblasts, that form the so-called bone multicellular unit (3). The activity of the bone multicellular unit is orchestrated by osteocytes

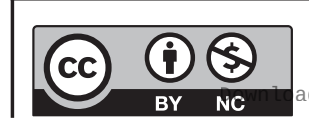

This work is licensed under a Creative Commons Attribution-NonCommercial 4.0 International License. ded from Bioscientifica.com at 04/26/2023 01:59:03PM 
(cells of the osteoblastic lineage trapped in the bone matrix), which in response to local biomechanical factors (bone micro-damage and mechanical strain) and systemic hormonal influences, initiate the bone remodeling cycle, in which bone resorption and formation are coupled in time and space (4). Bone remodeling allows the adult human skeleton to replace the old and damaged tissue and promptly adapts to maintain calcium homeostasis. Uncoupling of this process leads to bone loss (if resorption exceeds formation) or accumulation of bone (if formation exceeds resorption).

\section{Thyroid hormones}

Thyroid hormones (thyroxine, T4 and triiodothyronine, T3) have an important effect on bone remodeling. Their effects are mainly mediated by the interaction of available intracellular T3 (either entered into the cells from the bloodstream or locally produced by deiodination of T4) with the nuclear thyroid hormone receptor $\alpha$ isoform in osteoblasts; the action of thyroid hormones on osteoclasts and osteocytes remains yet to be defined (5). T3 stimulates directly or indirectly osteoblast activities (differentiation and proliferation, and synthesis and mineralization of bone matrix) by pathways which involve cytokines and growth factors. T3 also stimulates osteoclastogenesis and osteoclast activity, but it is unclear whether these effects are direct or mediated by the action of $\mathrm{T} 3$ on osteoblasts, osteocytes or other bone marrow cells (5).

\section{TSH}

The expression of TSH receptor (TSHR) was firstly reported in osteoblasts by Inoue et al. in 1998 (6) and in osteoclasts by Abe et al. in 2005 (7). No data is available on osteocytes. In vitro experiments have shown contradictory effects on osteoblast differentiation and function. Moreover, the intracellular pathways involved following TSHR activation have not been yet established (5). Conversely, some studies have shown that TSHR activation leads to inhibition of osteoclastogenesis and osteoclast function. These effects are complex and appear to be mediated by stimulation of osteoprotegerin transcription (8) and inhibition of tumor necrosis factor $\alpha$ (TNF $\alpha)$ transcription (9).

\section{Rationale of TSH suppressive therapy with levothyroxine}

TSH suppressive therapy consists in the administration of levothyroxine (LT4) in order to reduce serum TSH levels below the normal range, maintaining normal levels of serum free T4 (FT4) and free T3 (FT3). Based on TSH levels, suppression is mild when TSH is maintained between 0.1 to $0.5 \mathrm{mU} / \mathrm{L}$, moderate when TSH is maintained between $0.1 \mathrm{mU} / \mathrm{L}$ to 0.01 and severe when TSH is below $0.01 \mathrm{mU} / \mathrm{L}$. Suppressive therapy can be finely tuned individually, thanks to the high sensitivity of the third-generation TSH assays that have a detection limit ranging between 0.004 and $0.01 \mathrm{mU} / \mathrm{L}(10)$.

TSH suppressive therapy is aimed at reducing and eventually abolishing the stimulatory effect of TSH on function and on growth of thyroid follicular cells.

Numerous studies have proven the utility of TSH suppressive therapy in patients with DTC. A meta-analysis of 10 studies from the 1970s to the 1990s showed that TSH suppressive therapy was useful in decreasing mortality and morbidity associated with DTC (11). It is worth noting that in these studies the assessment of residual disease was not based on the use of sensitive modern tools for the evaluation of recurrence of DTC, i.e. neck ultrasound and ultrasensitive thyroglobulin assays. Subsequent studies based on the data of the registry of the American National Thyroid Cancer Treatment Cooperative Study Group, where sensitive diagnostic tools, namely neck ultrasound and ultrasensitive serum thyroglobulin assays were generally employed, confirmed the utility of TSH suppressive therapy in patients at high risk of recurrence $(12,13)$. Finally, the most recent analyses of the same registry data in 4941 patients (median follow-up of 6 years) showed no benefit on survival when comparing patients with undetectable vs subnormal serum TSH levels in any stage of DTC (14).

To date only one prospective randomized clinical trial has been performed in this scenario. Sugitani et al. randomized 441 Japanese patients with DTC to receive or not receive TSH suppressive therapy. At the end of the follow-up (median 7 years), there was no difference in the disease-free survival (DFS) between the two groups, even when high-risk patients were analyzed separately (15).

The indications for TSH suppressive therapy in patients with DTC have changed over the years. In the 2009 American Thyroid Association (ATA) guidelines for the management of DTC, moderate TSH suppressive therapy was recommended for all patients at high or intermediate risk of recurrence and mild TSH suppressive therapy for patients with low risk (Recommendation \#40) (16). In the revision of these guidelines published in 2015 , the indication for TSH suppressive therapy is based on the response to the initial therapy and the ongoing risk stratification, considering not only their benefit on outcome of DTC,

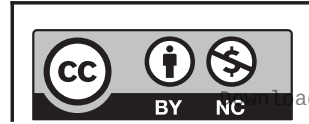

This work is licensed under a Creative Commons Attribution-NonCommercial 4.0 International License. ded from Bioscientifica.com at 04/26/2023 01:59:03PM 
but also any risk associated with exogenous thyrotoxicosis, namely menopause, osteopenia or osteoporosis, age $>60$ years, and history of atrial fibrillation (17) (Table 1).

The 2015 ATA guidelines also suggest that patients with DTC with a low preoperative risk can be treated either with total thyroidectomy or lobectomy (17). Few studies have evaluated the benefit of TSH suppressive therapy in the latter group. In a retrospective analysis, 446 Korean patients with low-risk, small DTC who underwent lobectomy and prophylactic lymph node dissection were treated or were not treated with TSH suppressive therapy and were monitored for a median of 8.6 years. Patients were assigned to one of the following groups of serum TSH $(<0.5 \mathrm{mU} / \mathrm{L}, 0.5-1.9 \mathrm{mU} / \mathrm{L}, 2.0-4.4 \mathrm{mU} / \mathrm{L}$, and $>4.5 \mathrm{mU} / \mathrm{L}$ ) according to values obtained in $>75 \%$ of multiple TSH determinations. No difference in DFS was observed between patients who had or had not 'suppressed' serum TSH ( $<2.0 \mathrm{mU} / \mathrm{L})$, even though the rate of biochemically indeterminate response was significantly higher in those whose serum TSH $>2.0 \mathrm{mU} / \mathrm{L}$ (18). The authors suggested that LT4 therapy should only be given to patients with post-operative hypothyroidism (18). On the basis of this limited data, the 2015 ATA guidelines do not recommend TSH suppressive therapy in patients with low-risk DTC treated with lobectomy (17).

\section{Effects of TSH suppressive therapy on the human skeleton}

Thyroid hormones have a fundamental role in the regulation of adult bone turnover and many studies have evaluated the effects of their excess on bone remodeling and on the risk of osteoporosis and fragility fractures.

\section{Bone mineral density (BMD)}

Bone mineral density (BMD) estimated by dual X-ray absorptiometry (DXA) is commonly used to evaluate bone health and fracture risk. Given the good reliability and reproducibility, and low costs, BMD estimated by DXA became the reference standard for the diagnosis of osteoporosis and for fracture risk stratification $(19,20)$. It is well known that for each standard deviation decrease in BMD there is a two-fold increase in fracture risk (21).

In an historical study by Ross et al., radial BMD was measured by single photon absorptiometry in 28 white premenopausal females who received TSH suppressive therapy (TSH $<0.1 \mathrm{mU} / \mathrm{mL}$ ) for 5 years or more. A significant BMD reduction (about 10\% vs normal controls) was observed in women receiving LT4 therapy for 10 years or more (22).

Since then osteoporosis become a major concern for the endocrinologists, several studies have evaluated the effect of chronic LT4 therapy on bone mass mostly in preand postmenopausal women, but also in men $(23,24)$. Our group has contributed to this topic with studies involving women and men in long term TSH suppressive therapy for DTC $(23,25)$. We found no significant difference in BMD between 47 premenopausal women chronically treated (mean 10.1 years) with suppressive doses of LT4, individually adjusted (to use the minimal dose) and aged and matched controls (23). In a cross-sectional analysis, which included 34 men who were given the minimal suppressive doses of LT4 for a mean of 10.2 years, we found no significant difference in BMD at any site (lumbar spine, femoral neck, Ward's triangle, and trochanter) between patients and age- and weight-matched controls. In addition, no correlation was shown between BMD and the duration of therapy, cumulative or for daily doses of LT4 and serum levels of FT3 and FT4 (25).

Several other studies have addressed the influence of TSH suppressive therapy on BMD in women, with variable results due to difference in the study design (cross-sectional, longitudinal, case-control), in number and type of patients enrolled (male, premenopausal or postmenopausal women) and in follow-up duration.

Table 1 Indication for TSH suppressive therapy in patients with differentiated thyroid cancer according to the ongoing risk stratification ${ }^{a}$.

\begin{tabular}{|c|c|c|c|c|c|}
\hline \multirow{2}{*}{$\begin{array}{l}\text { Thyroid surgery } \\
\text { Response }\end{array}$} & \multicolumn{4}{|c|}{ Total thyroidectomy } & \multirow{2}{*}{$\begin{array}{l}\text { Lobectomy } \\
\text { Low-risk patients }\end{array}$} \\
\hline & Excellent $^{\mathrm{b}}$ & Indeterminate $^{c}$ & Biochemical incomplete $^{d}$ & Structural incomplete & \\
\hline \multirow{2}{*}{ TSH suppression } & No & Mild & Mild & Moderate & No \\
\hline & $\mathrm{TSH} \geq 0.5 \mathrm{mU} / \mathrm{mL}$ & TSH $0.1-0.5 \mathrm{mU} / \mathrm{L}$ & TSH $0.1-0.5 \mathrm{mU} / \mathrm{L}$ & $0.1-0.01 \mathrm{mU} / \mathrm{L}$ & $\mathrm{TSH} \geq 0.5 \mathrm{mU} / \mathrm{mL}$ \\
\hline $\begin{array}{l}\text { Benefit/risk } \\
\text { assessment }\end{array}$ & \multicolumn{5}{|c|}{$\begin{array}{l}\text { Consider potential harm of exogenous thyrotoxicosis (atrial fibrillation, osteoporosis, osteopenia, } \\
\text { tachycardia, older age, menopause) and eventually downgrade the TSH target values }\end{array}$} \\
\hline
\end{tabular}

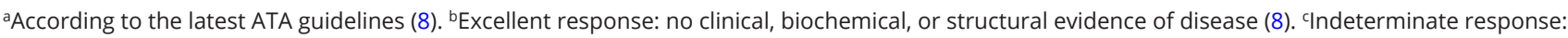
nonspecific biochemical or structural findings that cannot be confidently classified as either benign or malignant. This includes patients with stable or declining Tg antibody levels without definitive structural evidence of disease (8). ${ }^{\mathrm{dBiochemical}}$ incomplete response: abnormal Tg or rising Tg antibody levels in the absence of localizable disease (8). eStructural incomplete response: persistent or newly identified loco-regional or distant metastases (8). 
These studies have been summarized over the years in five meta-analysis $(26,27,28,29,30)$. The results of these five meta-analyses substantially agree with our findings, showing that TSH-suppressive therapy was deleterious on BMD in postmenopausal but safe in premenopausal women and men $(26,27,28,29,30)$. In detail, Faber et al., analyzed 13 case-controls studies which showed a significantly greater decline of BMD during TSH suppressive therapy in postmenopausal compared to premenopausal women. The estimated year loss was $0.13 \%$ in the former and $1 \%$ in the latter (26). Heemstra et al. reported similar results analyzing 21 studies involving pre- and postmenopausal women given TSH suppressive therapy for DTC (27). More recently, Papalentiou et al. showed more conflicting results among postmenopausal women. They analyzed 17 clinical studies, 4 were longitudinal and 13 cross-sectional. In longitudinal trials, TSH suppressive therapy was associated with a higher reduction of BMD in postmenopausal women compared to controls. Among cross-sectional studies, however, 5 studies reported a reduction of BMD, 6 studies indicated no change and 2 studies showed an increase. It is worth noting that the studies with conflicting results enrolled a limited number of patients (an average of 30) with a short follow-up (mean less than 3 years) (28). Yoon et al. limited the evaluation to cross sectional studies with a control group, and found that BMD at lumbar spine and femoral neck in premenopausal women (8 studies, 183 patients and 227 controls) was significantly higher in patients compared to controls, whereas there was no difference at the total hip. Conversely, in postmenopausal women (10 studies, 318 patients and 538 controls) lumbar spine and total hip BMD, but not femoral neck, were significantly lower in patients compared with controls (29). Finally, recently Wang et al. analyzed 11 case control studies and found no difference in BMD in the lumbar spine and femoral neck in women independently of the menopausal status (30). Although less information is available on the effect of TSH suppressive therapy on the BMD in men, the data derived from the above-mentioned meta-analyses showed no deleterious effect $(27,28,29,30)$. Heemstra et al. (8 studies included) showed no impact on BMD among a total of 147 men in TSH-suppressive therapy (27). Only a mild deleterious effect on BMD was reported by one study in which both patients who received TSH suppressive therapy and patients with Graves' disease were enrolled (31). Yoon et al. evaluated four case-control studies (66 patients and 67 controls) and none of them showed a significant difference between patients and controls (29)
Finally, similar results were recently reported by Wang et al. (30).

In summary, TSH suppressive therapy is associated with bone loss in postmenopausal but not premenopausal women and men. The safety of LT4 suppressive therapy in premenopausal women suggests a protective role of estrogen on LT4-induced bone loss. This hypothesis is supported by the study of Schneider et al., who evaluated BMD at the lumbar spine, hip and radius in 991 white postmenopausal women (age range 50-98 years) enrolled in a study on osteoporosis (32). The cohort included 196 women taking the thyroid hormone for a mean duration of 20.4 years and 795 women who were not using the thyroid hormone. The use of LT 4 doses $\geq 1.6 \mu \mathrm{g} / \mathrm{kg}$ body weight, but not for lower doses, was associated with lower BMD at any site compared with 'not users', after correction for several confounding factors. Of note, BMD among women taking LT4 doses $\geq 1.6 \mu \mathrm{g} / \mathrm{kg}$ and estrogens was higher than in women taking the same dose of LT4. Finally, women taking LT4 and estrogen had BMD values similar to those of women taking only estrogens (32). Unfortunately, these compelling results were not further investigated in prospective studies.

LT4 suppressive therapy nowadays has more limited indications; however, according to the latest ATA guidelines, it might still play a role in patients with DTC and indeterminate, biochemical and structural incomplete responses (Table 1). In these patients the benefit/risk ratio needs to be evaluated individually. This issue has been addressed in a cohort of 771 patients (73.8\% women) with low-intermediate risk of recurrence treated by total thyroidectomy and followed for a median of six and half years (33). Patients were grouped according to the available serum TSH results during the study: suppressed (median TSH $\leq 0.4 \mathrm{mU} / \mathrm{mL}$ ) and not suppressed (median TSH $>0.4 \mathrm{mU} / \mathrm{mL}$ ). Recurrence occurred in $43(5.6 \%)$ patients, with no difference according to median serum TSH. Atrial fibrillation was diagnosed in 17 patients (2.3\%) and osteoporosis in 29 patients (3.9\%), the latter at a statistically significant higher rate in women with suppressed TSH compared with those with a nonsuppressed median TSH (HR 3.5, (CI 1.2-10.2)) (33). This data is consistent with the observation of Flynn and colleagues in 17,684 patients (excluding those treated for thyroid cancer or euthyroid goiter; $85.9 \%$ female with a mean age of 60.3 years) living in Tayside, Scotland, who were taking LT4 for a median of 4.5 years. Patients with suppressed TSH $(\leq 0.03 \mathrm{mU} / \mathrm{L})$, but not those with low TSH (0.04-0.4 mU/L) had an increased risk of cardiovascular https://ec.bioscientifica.com https://doi.org/10.1530/EC-20-0167 (c) 2020 The authors Published by Bioscientifica Ltd
This work is licensed under a Creative Commons Attribution-NonCommercial 4.0 International License. ed from Bioscientifica.com at 04/26/2023 01:59:03PM 
disease (HR 1.37 (1.17-1.60)), dysrhythmias (1.60 (1.10-2.33)) and osteoporosis (2.02 (1.55-2.62)) (34).

\section{Trabecular bone score (TBS) and quantitative computed tomography (QCT)}

DXA is an excellent tool to assess bone quantity and, as previously mentioned, low BMD by DXA is a useful predictor for fractures. Nonetheless, it is well known that most fractures occur in women with normal levels of $\operatorname{BMD}(21,35)$. Alterations of bone microarchitecture, not detected by DXA, are associated with an increased risk of fracture, independently from $\operatorname{BMD}(36,37)$, as often seen in some endocrine disorders, namely acromegaly, Cushing's disease, hyperparathyroidism and hyperthyroidism $(38,39,40)$. Another classical example is glucocorticoid-induced osteoporosis, where for the same BMD the risk of fracture is higher in postmenopausal women taking glucocorticoids compared to 'not users' (41). In this clinical scenario, techniques that evaluate the bone quality are particularly useful.

Trabecular bone score (TBS) is a textural index that is a result of computed evaluation of pixel grey-level variations in lumbar spine DXA images. TBS can be used as an index of the bone microstructure and it is strongly related to 3D bone structure parameters, such as the trabecular number, the trabecular separation, and connectivity $(42,43)$.

Different studies have evaluated the relationship between thyroid function and TBS. Hwangbo et al. evaluated TBS and BMD in 1736 euthyroid subjects (648 postmenopausal women and 728 men). No association was shown between lumbar BMD and thyroid hormones levels, whereas high-normal FT4 levels were negatively correlated with TBS in postmenopausal women (44). Very recently, Kuzma et al. showed a lower TBS value in 21 premenopausal women with untreated Graves' disease compared to healthy controls (45). Among patients given TSH suppressive therapy, different studies showed an impairment of TBS especially in postmenopausal women. De Mingo Dominguez et al. analyzed BMD, TBS, and bone turnover markers in 61 premenopausal and 84 postmenopausal Caucasian women at baseline (within 3 months after total thyroidectomy) and after 10 years of TSH suppressive therapy. Postmenopausal women showed a lower TBS compared to premenopausal women and there was no correlation between changes in TBS and BMD (46). In another retrospective cohort study involving 273 postmenopausal women with DTC treated with
TSH suppressive therapy, Moon et al. showed that TSH suppressive therapy was associated with lower TBS and this association was independent of age, BMI, and BMD (47). In addition, they showed that TBS was significantly lower in patients receiving TSH suppressive therapy for 5 years or more compared with those treated for less than three years, after adjustment for age, BMI and BMD (47).

High-resolution quantitative CT (HR-QCT) is a noninvasive, low radiation method for studying volumetric bone mineral density (vBMD) and bone microarchitecture (48). It can be performed at lumbar site (central QCT, CQCT) or at distal radius and tibia (peripheral QCT, pQCT). Computed image analysis provides several parameters related to bone structures as bone volume, trabecular thickness, trabecular bone mineral density, cortical thickness, cortical bone mineral density, etc. Its application in clinical research has increased our knowledge of bone architecture and bone impairment across a wide range of metabolic disorders $(48,49)$.

Few studies have evaluated bone architecture using QCT in patients given TSH suppressive therapy (50, 51). Tournis et al. performed pQCT and DXA at hip and lumbar spine in 80 women (40 premenopausal and 40 postmenopausal) treated with TSH suppressive therapy for DTC and in 89 controls. BMD by DXA did not differ between pre- and postmenopausal women. Conversely, pQCT showed a lower trabecular bone mineral content, area and vBMD in postmenopausal women given TSH suppressive therapy compared to controls (50). Moreover, Kim et al. evaluated by DXA, TBS and cQCT 81 postmenopausal women (median age 58 years) receiving TSH suppressive therapy for DTC for a median of 5 years. When DXA and cQCT were compared, the diagnosis of osteoporosis was higher using CQCT rather than DXA (31 vs $21 \%$ respectively). In addition, in 46 patients with normal T-score by DXA, the diagnosis shifted to osteopenia and to osteoporosis when volumetric BMD (vBMD) by cQCT was considered. When TBS and DXA were compared, there was no significant correlation between BMD and TBS. Finally, when TBS and vBMD were compared, TBS was lower in patients with osteopenia and osteoporosis than in those with normal value of vBMD on cQCT (51).

This data supports the idea that the TSH suppressive therapy induces microarchitecture alterations of bones and that this qualitative impairment is better evaluated using sensitive techniques (TBS or p/cQCT) rather than BMD estimated by DXA.
This work is licensed under a Creative Commons Attribution-NonCommercial 4.0 International License. ded from Bioscientifica.com at 04/26/2023 01:59:03PM via free access 


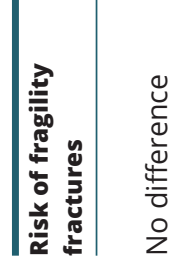

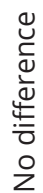

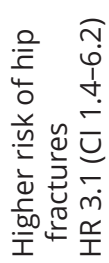

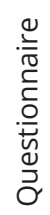

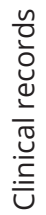

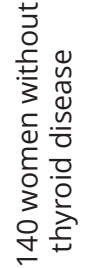

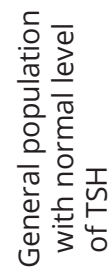

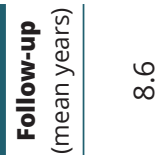

$\dot{\Sigma}$

๓े

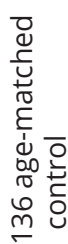

$\frac{\sqrt{\frac{\pi}{x}}}{x}$

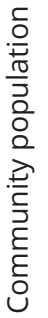

ㅇ

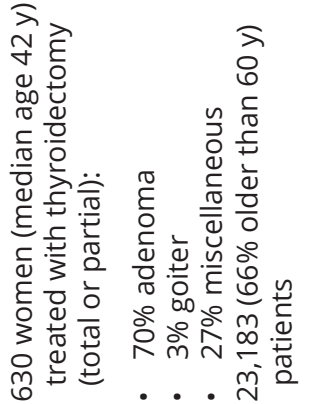

$\frac{ㄷ}{ㅇ ㅡ ㅁ ~}$

$\frac{1}{7}$
$\frac{0}{2}$
$\frac{0}{2}$
$\frac{0}{0}$

ษั

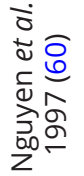
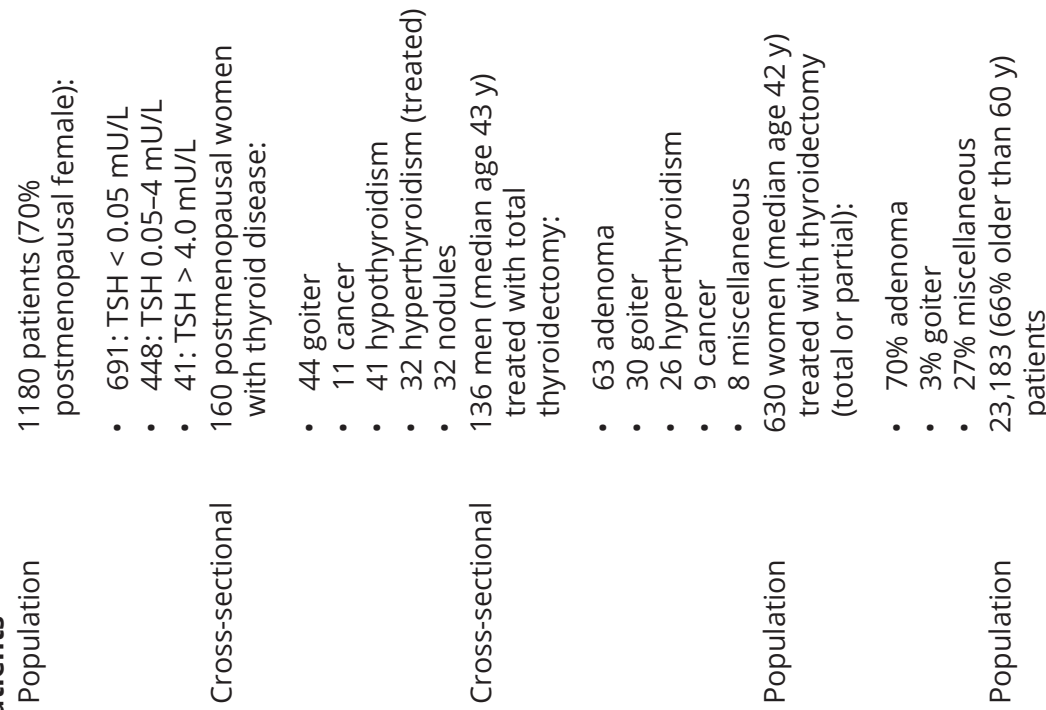

$\stackrel{\nwarrow}{\unlhd}$

ฐ

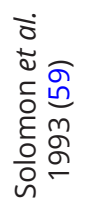

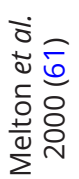

을 뒁

는 $\cong \widehat{0}$

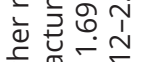

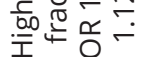

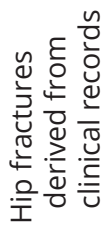

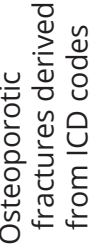

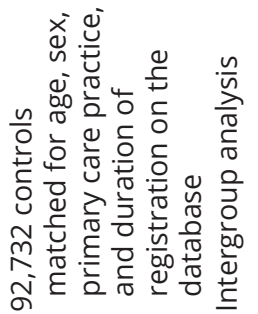

ต்

$\infty$
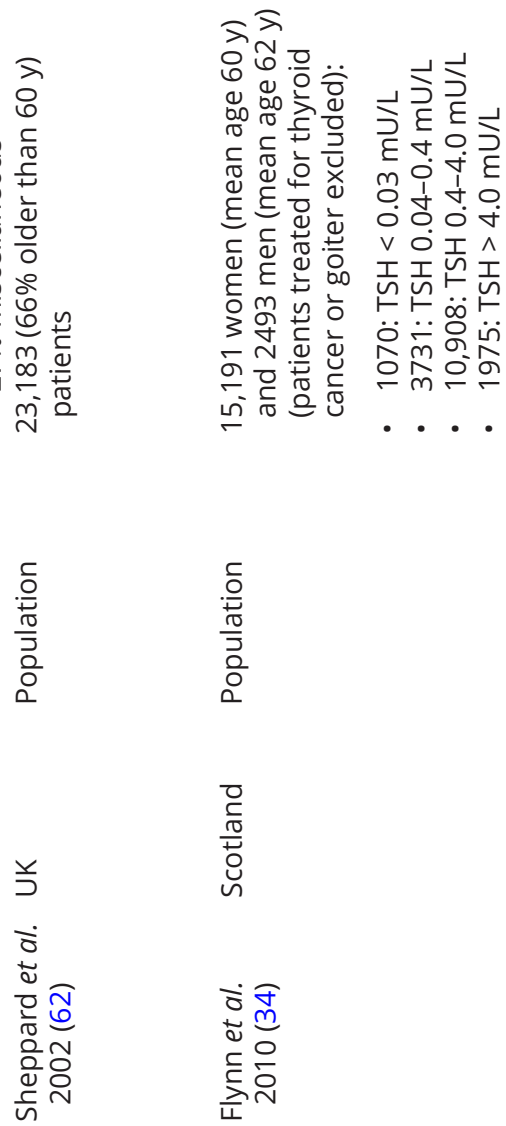


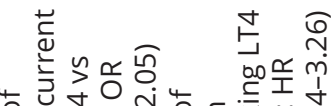

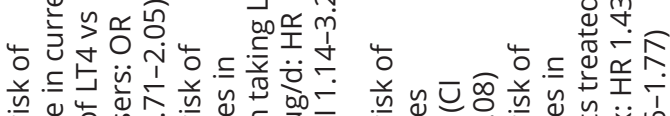

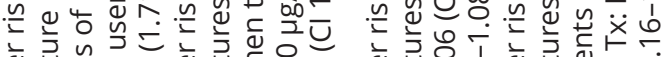

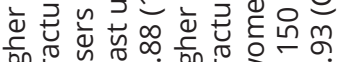

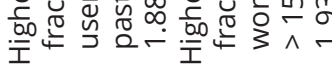

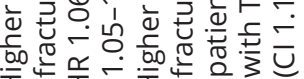

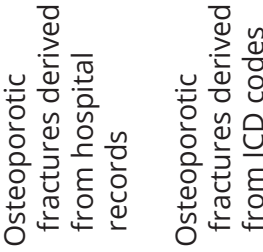
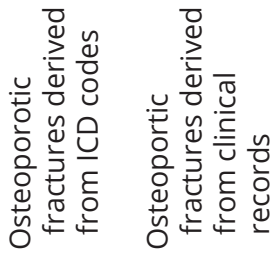

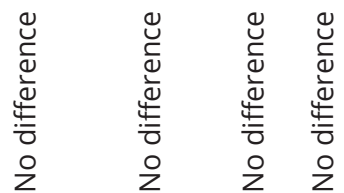

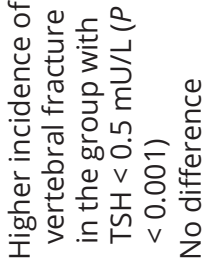

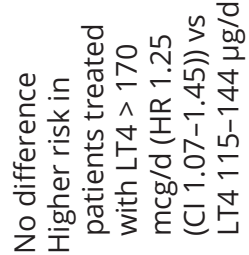

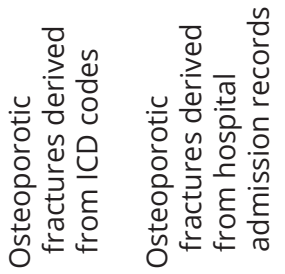

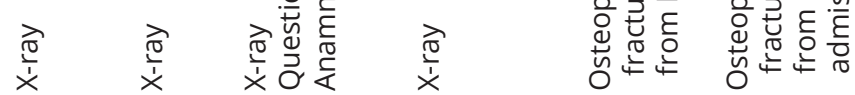
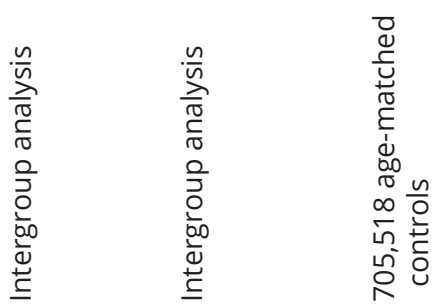

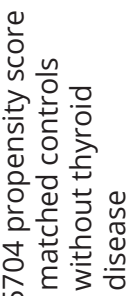

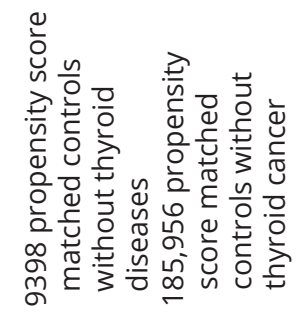

$\stackrel{m}{m} \quad \stackrel{n}{\leftarrow} \quad 0$

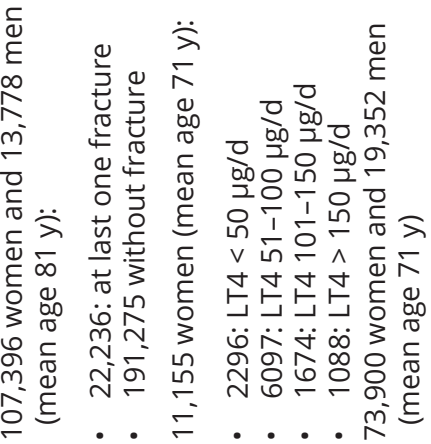
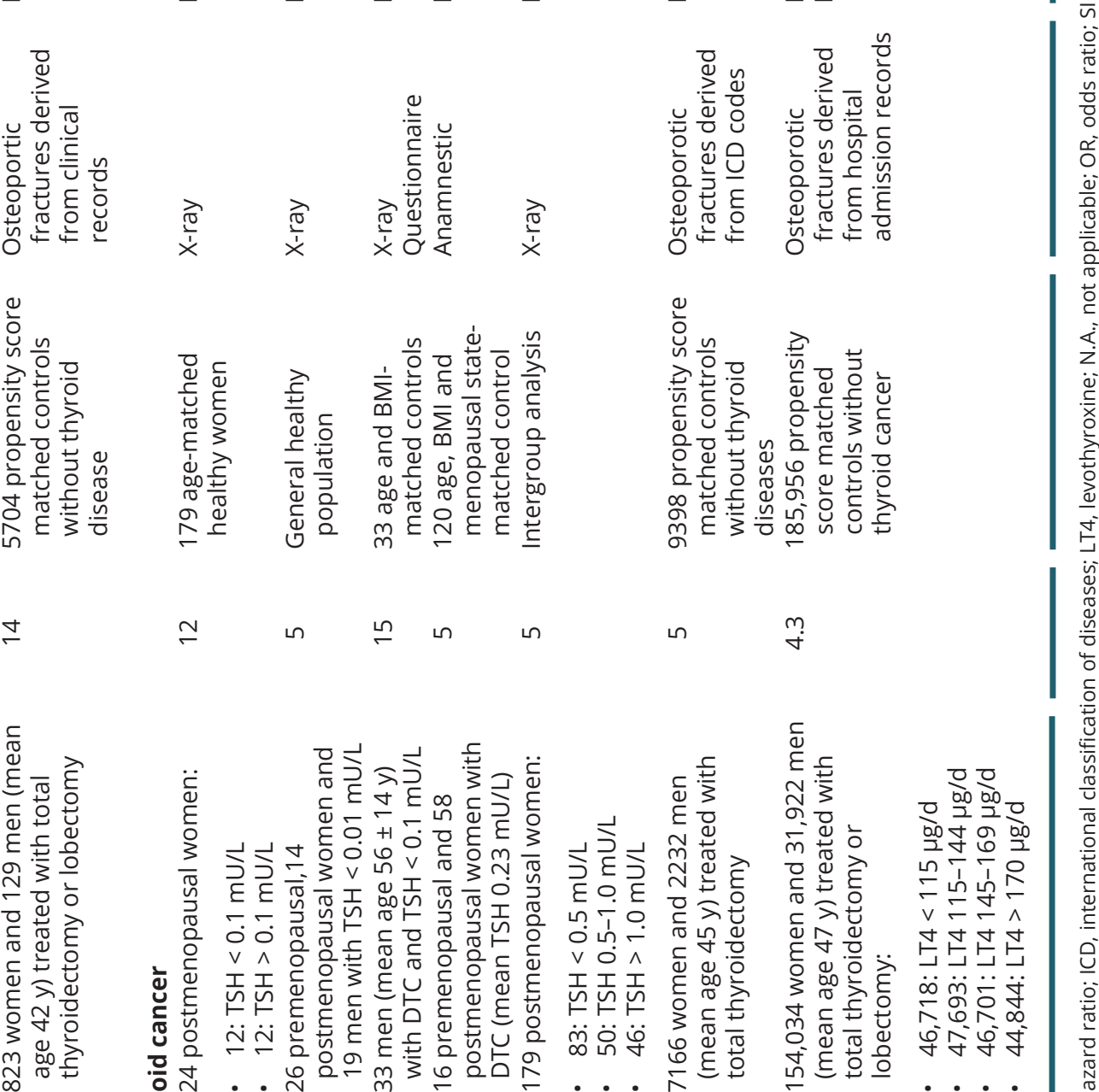

$\stackrel{+}{\Xi}$

$\stackrel{2}{2}$

ก $\stackrel{\circ}{n}$ เ

$\stackrel{m}{+}$

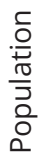

$\frac{\substack{0 \\ \frac{0}{2}}}{\frac{2}{0}}$

$\begin{array}{ll}\frac{1}{\circ} & \frac{2}{0} \\ \frac{0}{0} & \frac{0}{7} \\ \frac{0}{0} & \frac{0}{0} \\ \frac{0}{0} & \frac{0}{0}\end{array}$

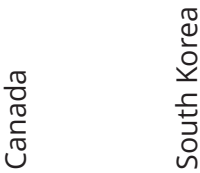

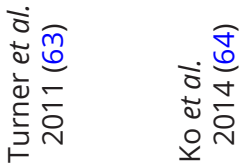

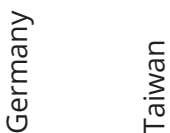

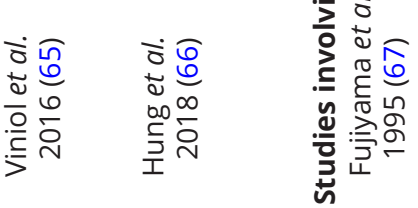

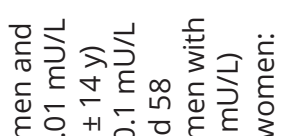

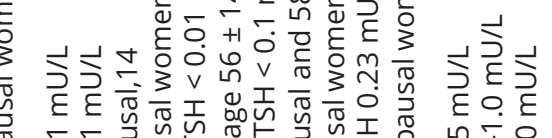

त्र

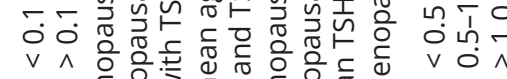
o응ㄷำ

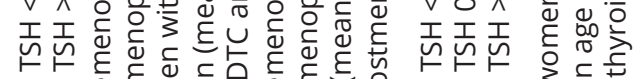
نं山े $\because \simeq$ 흔

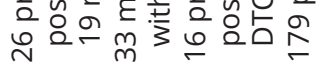
$\infty$ iी ध

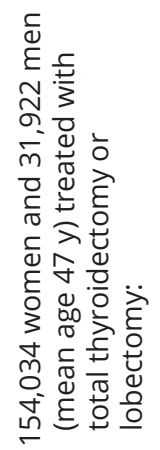

$\frac{10}{0.00}$ 응 만하음 난ㄷㅇ

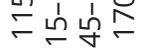
在过寺卞

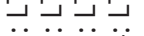
舟 守守守求

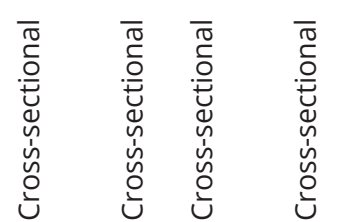

$\begin{array}{ll}\frac{1}{\circ} & \frac{.}{0} \\ \frac{0}{0} & \frac{0}{0} \\ \frac{0}{0} & \frac{0}{0} \\ 0 & \frac{0}{0}\end{array}$

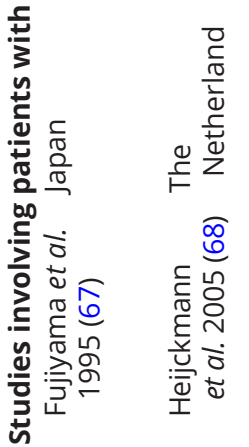

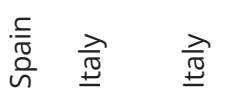

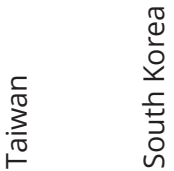

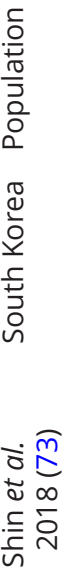




\section{Fracture risk}

Osteoporotic fractures are a common health problem, particularly in postmenopausal women, and are associated with high morbidity and mortality (52).

Hyperthyroidism is associated with an increased risk of fractures. This association was firstly shown in 1995 by Cummings et al. in 9516 white women aged 65 years or older for a median follow-up of 4 years. During this period, 192 women had non-traumatic hip fractures. Previous hyperthyroidism, current use of anticonvulsant drugs, family history of hip fracture, and use of LT4 therapy were the major risk factors (53). It should be highlighted that LT4 therapy was no longer a risk factor, when patients with prior hyperthyroidism were excluded from the analysis (53).

Many studies involving a large number of subjects have evaluated the association between 'endogenous' (toxic adenoma and toxic multinodular goiter) subclinical/mild thyroid hormone excess and the risk of fractures, particularly in postmenopausal women (54, 55). Garin et al. evaluated 4936 individuals of 65 years or older monitored for a median of 12 years. No association was found between subclinical thyroid dysfunction (hypothyroidism and hyperthyroidism) and the incidence of hip fractures (54). In the same study, no association was shown between subclinical thyroid dysfunction and BMD at the lumbar spine, total hip, or femoral neck in 1300 individuals tested by DXA (54). In contrast Murphy et al. showed an association between FT4 and FT3 levels at the upper normal range and the risk of nonvertebral fracture, among 2400 postmenopausal women (55). After adjustment for BMI, age and BMD, the risk of nonvertebral fracture was increased by $20 \%$ in women with higher FT4 levels. In addition, higher levels of TSH showed a protective effect, with a risk reduction of 35\% (55). This data seems to be concordant with the results of different meta-analysis which focused on the subclinical alterations of thyroid function and the fracture risk (56, 57). In a systematic meta-analysis including about 50,000 participants from 7 high quality studies, Wirth et al. showed that the hazard ratios of subjects with subclinical hyperthyroidism were 2.16 (95\% CI 0.87 to 5.37) for hip fracture and 1.43 (95\% CI 0.73 to 2.78) for non-spine fractures compared to subjects with normal thyroid function (56). These results were confirmed by Blum et al., analyzing 13 prospective cohort studies involving more than 70,000 participants (57). The HR for hip fractures (1.36 (95\% CI 1.13 to 1.64$)$ ), and any fracture (1.28 (CI 1.06 to 1.43$)$ ), but not for non-spine fractures
(1.16 (95\% CI 0.95 to 1.41$))$ and spine fractures (1.51 (95\% CI 0.93 to 2.45$)$ ), were significantly higher in patients with subclinical hyperthyroidism than in subjects with normal thyroid function (57). Furthermore, in a subgroup analysis, these authors showed a negative correlation between TSH levels below 0.1 and the risk of fractures (57).

Several studies, mainly population-based, have evaluated the relationship between treatment with LT4 and fracture risk in unselected patients treated with LT4 and, with few exceptions $(58,59)$, an increased risk of osteoporotic fracture was found $(34,60,61,62,63,64,65$, 66) (Table 2). Noteworthy, although these studies included a large number of patients with an extensive follow-up, important data was often missing, namely the indication of LT4 therapy, the previous history of hyperthyroidism, the dosage of LT4 therapy, and the serum TSH values (Table 2).

Five cross-sectional studies, involving a limited number of patients, have focused on the risk of fracture in patients with DTC treated with TSH suppressive therapy $(67,68,69,70,71)$ (Table 2). Fujiyama et al. evaluated 24 postmenopausal women treated with total thyroidectomy for DTC and found no difference in the incidence of vertebral deformity nor in the rate of bone loss between patients and 179 age-matched controls (67). Similar results were reported in three successive casecontrol studies. In the first, Heijckmann et al. evaluated 59 patients (40 pre- and postmenopausal women and 19 men) receiving TSH suppressive therapy for DTC and found no difference in the rate of prevalent vertebral fracture between patients and NHANES (National Health and Nutrition Examination Survey) III reference group either in women or men (68). In the second study Reverter et al. evaluated 33 men (mean age $56 \pm 14$ years) given TSH suppressive therapy with a median of 15 years and found no difference in the rate of either prevalent or incident (asymptomatic; 18.8 vs 16.7\%) vertebral fractures between patients and 33 age-matched controls (69). In the third, Vera et al. retrospectively evaluated the rate of prevalent and incident major osteoporotic fractures and hip fractures in 74 women (78\% postmenopausal) with DTC with two or more BMD measurements and found no difference compared with a cohort of 120 euthyroid woman comparable for age, menopausal status and BMI, selected among patients evaluated for bone health (70). At variance with these studies, Mazziotti et al. evaluated the incidence of radiological vertebral fractures in 179 consecutive women (median age 59 years, all but one postmenopausal) treated with total thyroidectomy for

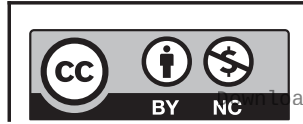

This work is licensed under a Creative Commons Attribution-NonCommercial 4.0 International License. ed from Bioscientifica.com at 04/26/2023 01:59:03PM 
DTC attending to an outpatient endocrine clinic and evaluated for bone health (personal communication from the authors) (71). Patients were divided in three groups according to the TSH levels during LT4 therapy (group 1: TSH $<0.5 \mathrm{mU} / \mathrm{L}$; group 2: TSH between 0.5 $\mathrm{mU} / \mathrm{L}$ and $1 \mathrm{mU} / \mathrm{L}$; group 3: $\mathrm{TSH}>1 \mathrm{mU} / \mathrm{L})$. Vertebral fractures were detected in $28.5 \%$ of patients with higher prevalence among women of group 1 compared to other two groups (44.6, 24 and 3.3\%, respectively). Interestingly, the prevalence of vertebral fractures in group 1 was independent of BMD (normal, osteopenia or osteoporosis), whereas in groups two and three it was higher in the osteoporotic than in the other two groups. Finally, in the whole cohort, vertebral fractures were independently associated with serum $\mathrm{TSH}<1 \mathrm{mU} / \mathrm{mL}$, age and duration of LT4 therapy (71). Unfortunately, this interesting study lacks a control group.

To our knowledge, only two population-based studies have investigated the risk of osteoporotic fracture in patients given TSH suppressive for DTC $(72,73)$ (Table 2). Lin et al. evaluated a retrospective cohort of 9398 patients with thyroid cancer (69.5\% aged less than 49 years, $75.8 \%$ women) newly diagnosed in Taiwan during the period 1999-2011, who received $(n=8860)$ or didn't receive $(n=538)$ LT4 therapy and compared the risk of fractures between patients and the propensity score matched non-thyroid controls $(n=9398)$. The mean follow-up was $6.5,5.5$ and 6.6 years, respectively. The incidence of osteoporotic fractures (ICD-9-CM code 733.1) did not differ between thyroid cancer patients (adjusted HR 1.32, CI 0.93-1.87) and non-thyroid controls and between LT4treated (adjusted HR 3.42, CI 0.83-14.1) and untreated patients. Conversely, the incidence of osteoporosis was higher in thyroid cancer patients (adjusted HR 1.40; CI 1.22-1.61) than in non-thyroid controls and in LT4treated (adjusted HR 2.02; CI 1.18-3.44) than in untreated patients (72). Conversely, Shin et al. compared the risk of fractures between 154,034 women and 31,922 men (mean age 47 years) with DTC treated with LT4 and 185,956 propensity score matched non-thyroid controls. Patients were clustered in four groups according to daily dose of LT4 (group $1=\mathrm{LT} 4<115 \mu \mathrm{g} /$ day; group $2=\mathrm{LT} 4$ 115-144 $\mu \mathrm{g} /$ day; group 3=LT4 145-169 $\mu \mathrm{g} /$ day; group $4=\mathrm{LT} 4>170 \mu \mathrm{g} /$ day). The risk for osteoporotic fracture did not differ between patients and controls. Nevertheless, patients treated with the highest dosage of LT4 showed a higher risk for fractures compared to patients treated with lower dosage (73).

These discrepancies could be partially explained by different criteria of enrollment, different technique used for detection of vertebral fractures, and different duration of follow-up. In addition, no data is available on the risk of hip fractures and other nonvertebral fractures among patients given TSH suppressive therapy. On the basis of these mixed results, the effect of TSH suppressive therapy on fracture risk remains uncertain.

\section{Clinical approach to TSH suppressive therapy induced bone loss}

Thyroid hormones stimulate bone turnover in adults by increasing osteoclastic bone resorption. TSH suppressive therapy is still indicated in a subgroup of patients with DTC with incomplete response and high risk of recurrence. In this context, TSH suppressive therapy in postmenopausal women may be associated with bone loss and eventually with fractures. Therefore, bone health (BMD and/or TBS (preferably)) should be evaluated in postmenopausal women who are already given chronic treatment with LT4 or planning to be treated for more than 3-5 years (Fig. 1) and repeated every 2 years thereafter. In addition, fracture assessment tools $\left(\right.$ QFracture $^{\circledR}$ and FRAX ${ }^{\circledR}$ ) (74) could be used to guide individual management, particularly in those who already have other risk factors for osteoporosis and fractures. These algorithms include thyrotoxicosis (QFractrure ${ }^{\circledR}$ ) or hyperthyroidism (FRAX ${ }^{\circledR}$ ), but not TSH suppressive therapy. As far as FRAX ${ }^{\circledR}$ is concerned, even though TSH suppressive therapy is not among the risk factors, some authors for practical purpose, based on the 2.5- to 3.0-fold increased risk of hip fractures associated with serum TSH $<0.05 \mathrm{mU} / \mathrm{L}$, suggest to decrease by 1 the measured femoral neck hip score in women receiving or planning to start TSH suppressive therapy for at least 5 years (2). Routine evaluation of bone health in premenopausal women and men is not indicated, unless other risk factors are present. Limited data is available on the potential role played by antiresorptive agents to prevent bone loss. In a study involving 74 postmenopausal women with DTC and osteoporosis, alendronate therapy for 2 years increased BMD at the lumbar spine in those treated with LT4 for 3 years, but was less effective and not effective in those treated for 6 years and 9 years, respectively (75). Other antiresorptive drugs (estrogen, calcitonin, denosumab) could also be considered in selected cases (increased risk of fracture or significant decline of BMD/TBS during therapy), although no randomized clinical trials have tested these drugs in patients treated with LT4 suppressive therapy (Fig. 1). Finally, adequate calcium intake and, if needed, vitamin D supplementation, 
should also be considered, most importantly when planning antiresorptive therapy.

It is well known that both TSH suppressive therapy and bisphosphonates (oral and i.v.) are associated with an increased risk of atrial fibrillation (76). Therefore, the bone benefit of giving bisphosphonates to postmenopausal women receiving TSH suppressive therapy should be balanced with the compounded risk of both treatments to induce atrial fibrillation.

Table 3 summarizes some key points on practical indications concerning TSH suppressive therapy and bone health.

\section{Potential negative effects of low TSH on bone}

The skeletal consequences of TSH suppressive therapy have been until recently attributed to the relative increase of circulating thyroid hormones. Little attention was paid to the low/undetectable TSH levels, until the demonstration that TSHR is expressed on the surface of murine osteoblasts and osteoclasts and their precursors, suggesting that TSH might have direct effects on bone metabolism $(6,7)$. Abe et al. showed in a $\mathrm{Tshr}^{+/-}$knockout mouse model that a $50 \%$ reduction of the expression of TSHR on bone cells was associated with bone loss and focal osteosclerosis regardless of the levels of thyroid hormones (7). Further insight came from experiments using ex vivo bone marrow cultures from TSHR null, heterozygote and wild-type mice. Osteoblast and osteoclast differentiation was increased in cultures obtained from Tshr-null and heterozygote mice compared to wild type and was associated with increased expression of cell-specific markers. They also showed that TSH inhibited osteoblasts differentiation from stromal cells and type 1 collagen expression by downregulating Wnt and VEGF signaling. On the other hand, TSH reduced osteoclast differentiation from hematopoietic stem cells, by inhibiting the JNK/c-jun and NF-kB signaling induced by RANK-L and TNF $\alpha$. As a consequence, the reduction of TSH-TSHR signaling induced an overactivation of osteoclast activity leading to bone loss and osteoporosis (7). In a further study, Baliram et al. compared the skeletal phenotypes of wildtype and $\mathrm{Tshr}^{-/-}$mice that were rendered thyrotoxic by implantation of slow release 5-mg thyroxine pellets (77). Even though both groups of mice had undetectable TSH and similar serum T4 levels, $\mathrm{Tshr}^{-1-}$ mice lose more bone compared to wild-type mice, indicating that the lack of TSH signaling contributes to bone loss (77).

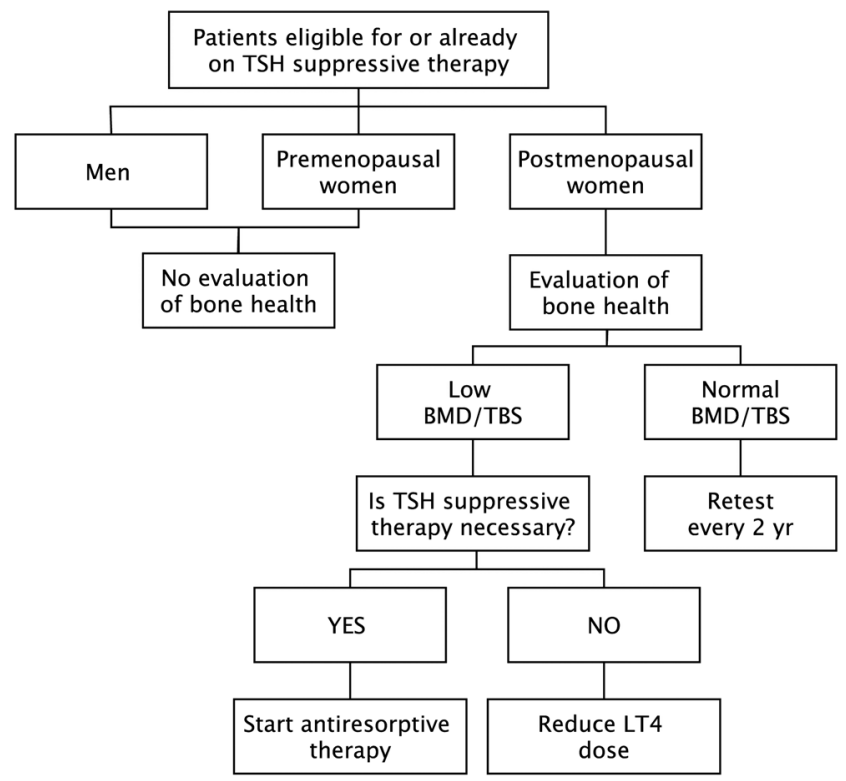

Figure 1

Evaluation of bone health in patients eligible for, or already on, TSH suppressive therapy and indication for antiresorptive therapy.

This data is in agreement with other studies that have shown a protective role of TSH on bone loss in aged ovariectomized rats $(78,79)$. In particular, Sun et al. demonstrated that intermittent injections of recombinant TSH were able to prevent bone loss in ovariectomized rats by blocking osteoclast activity. Moreover, they observed that the anabolic effect of TSH on bone metabolism persisted more than 4 weeks after injection (79).

In humans, an association between lower BMD and serum TSH has reported either in patients with subclinical/mild endogenous hyperthyroidism (undetectable serum TSH and FT4 in the normal range) (57) or in euthyroid individuals with a low serum TSH and relatively high, but still normal, serum FT4 (55). In both cases the association of low serum TSH with BMD could be related to the reciprocal relatively high serum FT4. Nonetheless, some studies provide some evidence for an independent role of TSH. Van Der Deure et al. investigated the association of serum TSH and FT4 with different bone parameters in a subgroup $(n=1327)$ of subjects enrolled in the Rotterdam study and showed that femoral BMD and cortical thickness increased with serum TSH levels, but FT4 was more strongly inversely correlated with the bone parameters (80). At multivariate analysis, however, both TSH and FT4 levels affected the bone status independently. In addition the authors showed that subjects harboring an activating polymorphism of TSHR (TSHR-Asp727Glu) had an increased bone density and bone mass (80). The same polymorphism of TSHR

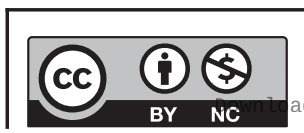

This work is licensed under a Creative Commons Attribution-NonCommercial 4.0 International License. ded from Bioscientifica.com at 04/26/2023 01:59:03PM via free access 
were associated with a greater BMD in other study (81). In other cross-sectional study involving more than 37,000 subjects of whom about 33,000 with normal thyroid function and 4000 with subclinical thyroid dysfunction, Kim et al. reported a positive correlation between TSH levels and BMD in all tested skeletal sites (lumbar spine, femur neck, total hip) (82). BMD increased continuously with TSH from subclinical hyperthyroidism to subclinical hypothyroidism in particular among patients with $\mathrm{T} 3$ in the highest tertile range. The authors concluded that there was a positive correlation between TSH levels and BMD in healthy men and women with normal levels of FT4 and, furthermore, that higher TSH levels could be protective on bone loss especially in patients with serum T3 levels in the upper normal range (82). The administration of human recombinant TSH (rhTSH) to patients with DTC undergoing thyroid remnant ablation with ${ }^{131}$ I after total thyroidectomy offers additional data on a direct effect of TSH on bone turnover $(83,84,85)$. In this setting serum thyroid hormone concentration remains unchanged, whereas serum TSH markedly increases. Over a period of 7-10 days after rhTSH administration there are both a reversible inhibition of bone resorption (decrease of serum c-terminal telopeptide, CTx, and no effect on serum osteoprotegerin) and a stimulation of bone formation (increase of serum bone alkaline phosphatase, BALP, and procollagen type 1 amino-terminal propeptide, $\mathrm{P} 1 \mathrm{NP}$ ) $(83,84,85)$.

It is important to note that alongside the abovementioned studies, which support a direct protective action of TSH on bone, other studies cast doubt on this aspect. One issue is to what extent the bone phenotype observed in $\mathrm{Tshr}^{--}$mice could reflect the consequences of severe congenital untreated hypothyroidism rather than the lack of TSH effects on bone. To address this issue Basset et al. compared the bone phenotype of the $\mathrm{Tshr}^{-/-}$ mouse with that of $\mathrm{Pax}^{-/-}$, another model of congenital hypothyroidism (86). Both models are characterized by lack of circulating thyroid hormones and elevated TSH, but functional TSHR the latter but not the former. The bone phenotype did not differ between the two models suggesting a predominant role of lack of thyroid hormones rather than the lack of TSH action, even though the effect of severe hypothyroidism could mask the skeletal action of TSH (86). Recently, Van Vliet et al. provided data that shed doubt on the protective effect of TSH on bone in humans (87). These authors carried out two-sample Mendelian randomization studies, using available data from the Genetic Factors of Osteoporosis
Table 3 TSH suppressive therapy and bone health: practical indication.

- TSH suppressive therapy should be used only when indicated

- Treatment should be individualized in order to use the lowest effective dose of LT4

- TSH suppressive therapy should be carefully monitored (yearly) by measurements of serum FT4 and TSH

- In premenopausal women and men chronically treated with TSH suppressive therapy or planning to be treated for several years (more than 3-5), there is no need to assess/ monitor bone health, unless other risk factors are present

- In postmenopausal women already treated with TSH suppressive therapy or planning to be treated for several years (more than 3-5) bone health should be evaluated/ monitored using BMD and/or TBS (preferably)

- Antiresorptive therapy could be considered in patients at increased risk of fracture or showing with a significant decline of BMD/TBS during TSH suppressive therapy

BMD, bone mineral density; LT4, levothyroxine; TBS, trabecular bone score.

(GEFOS) consortium. They found that none of the available 19 single nucleotide polymorphisms (SNPs) associated with serum TSH was associated with BMD at lumbar spine and femoral neck. Moreover, no association was found between 706 of the available SNPs in TSHR or genetic variants influencing the expression of TSHR and BMD at lumbar spine and femoral neck (87).

In conclusion, whether and to what extent low TSH levels, as opposed to solely high thyroid hormone levels, contribute to bone loss in endogenous or exogenous thyrotoxicosis remains to be defined.

\section{Conclusions}

TSH suppressive therapy still represents a useful tool to improve the outcome in patients with DTC and structural persistent disease after total thyroidectomy. In patients with biochemical incomplete response and indeterminate response, TSH suppressive therapy can be considered after a careful risk/benefit assessment, whereas TSH suppressive therapy is not recommended in patients with excellent response. TSH suppressive therapy is not indicated in patients with low-risk DTC treated with lobectomy.

TSH suppressive therapy has no harmful effects on bone health in premenopausal women and men. In postmenopausal women, TSH suppressive therapy is associated with bone loss, deterioration of bone architecture and, ultimately, increased risk of fractures. Other potential adverse events, particularly cardiovascular morbidity, should not be overlooked. Antiresorptive therapy could be considered in patients with increased
This work is licensed under a Creative Commons Attribution-NonCommercial 4.0 International License. ded from Bioscientifica.com at 04/26/2023 01:59:03PM 
risk of fracture or in patients showing a significant decline of BMD/TBS during LT4 therapy.

Current evidence on whether low TSH levels, as opposed to solely high thyroid hormone levels, might contribute to bone loss in endogenous or exogenous thyrotoxicosis remains controversial.

\section{Declaration of interest}

The authors declare that there is no conflict of interest that could be perceived as prejudicing the impartiality of this review.

\section{Funding}

This research did not receive any specific grant from founding agencies in the public, commercial or non-profit sectors.

\section{Author contribution statement}

Alessandro Brancatella and Claudio Marcocci wrote the manuscript.

\section{Acknowledgments}

The authors thank Laura Macrì for her technical help in drawing the figure.

\section{References}

1 Biondi B \& Cooper DS. Thyroid hormone suppression therapy. Endocrinology and Metabolism Clinics of North America 201948 227-237. (https://doi.org/10.1016/j.ecl.2018.10.008)

2 Williams GR. Is prophylactic anti-resorptive therapy required in thyroid cancer patients receiving TSH-suppressive treatment with thyroxine? Journal of Endocrinological Investigation 201437 775-779. (https://doi.org/10.1007/s40618-014-0110-9)

3 Raggatt LJ \& Partridge NC. Cellular and molecular mechanisms of bone remodeling. Journal of Biological Chemistry 2010285 25103-25108. (https://doi.org/10.1074/jbc.R109.041087)

4 Dallas SL, Prideaux M \& Bonewald LF. The osteocyte: an endocrine cell ... and more. Endocrine Reviews 201334 658-690. (https://doi. org/10.1210/er.2012-1026)

5 Bassett JHD \& Williams GR. Role of thyroid hormones in skeletal development and bone maintenance. Endocrine Reviews 201637 135-187. (https://doi.org/10.1210/er.2015-1106)

6 Inoue M, Tawata M, Yokomori N, Endo T \& Onaya T. Expression of thyrotropin receptor on clonal osteoblast-like rat osteosarcoma cells. Thyroid 19988 1059-1064. (https://doi.org/10.1089/thy.1998.8.1059)

7 Abe E, Marians RC, Yu W, Wu XB, Ando T, Li Y, Iqbal J, Eldeiry L, Rajendren G, Blair HC, et al. TSH is a negative regulator of skeletal remodeling. Cell 2003115 151-162. (https://doi.org/10.1016/s00928674(03)00771-2)

8 Ma R, Morshed S, Latif R, Zaidi M \& Davies TF. The influence of thyroid-stimulating hormone and thyroid-stimulating hormone receptor antibodies on osteoclastogenesis. Thyroid 201121 897-906. (https://doi.org/10.1089/thy.2010.0457)

9 Sun L, Zhu LL, Lu P, Yuen T, Li J, Ma R, Baliram R, Moonga SS, Liu P, Zallone A, et al. Genetic confirmation for a central role for TNFalpha in the direct action of thyroid stimulating hormone on the skeleton. PNAS 2013110 9891-9896. (https://doi.org/10.1073/ pnas.1308336110)

10 Spencer CA, Takeuchi M \& Kazarosyan M. Current status and performance goals for serum thyrotropin (TSH) assays.
Clinical Chemistry 199642 140-145. (https://doi.org/10.1093/ clinchem/42.1.140)

11 McGriff NJ, Csako G, Gourgiotis L, Lori G, Pucino F \& Sarlis NJ. Effects of thyroid hormone suppression therapy on adverse clinical outcomes in thyroid cancer. Annals of Medicine 200234 554-564. (https://doi.org/10.1080/078538902321117760)

12 Cooper DS, Specker B, Ho M, Sperling M, Ladenson PW, Ross DS, Ain KB, Bigos ST, Brierley JD, Haugen BR, et al. Thyrotropin suppression and disease progression in patients with differentiated thyroid cancer: results from the National Thyroid Cancer Treatment Cooperative Registry. Thyroid 19988 737-744. (https://doi. org/10.1089/thy.1998.8.737)

13 Jonklaas J, Sarlis NJ, Litofsky D, Ain KB, Bigos ST, Brierley JD, Cooper DS, Haugen BR, Ladenson PW, Magner J, et al. Outcomes of patients with differentiated thyroid carcinoma following initial therapy. Thyroid 200616 1229-1242. (https://doi.org/10.1089/ thy.2006.16.1229)

14 Carhill AA, Litofsky DR, Ross DS, Jonklaas J, Cooper DS, Brierley JD, Ladenson PW, Ain KB, Fein HG, Haugen BR, et al. Long-term outcomes following therapy in differentiated thyroid carcinoma: NTCTCS Registry Analysis 1987-2012. Journal of Clinical Endocrinology and Metabolism 2015100 3270-3279. (https://doi.org/10.1210/ JC.2015-1346)

15 Sugitani I \& Fujimoto Y. Does postoperative thyrotropin suppression therapy truly decrease recurrence in papillary thyroid carcinoma? A randomized controlled trial. Journal of Clinical Endocrinology and Metabolism 201095 4576-4583. (https://doi.org/10.1210/jc.20100161)

16 American Thyroid Association (ATA) Guidelines Taskforce on Thyroid Nodules and Differentiated Thyroid Cancer, Cooper DS, Doherty GM, Haugen BR, Kloos RT, Lee SL, Mandel SJ, Mazzaferri EL, McIver B, Pacini F, et al. Revised American Thyroid Association management guidelines for patients with thyroid nodules and differentiated thyroid cancer. Thyroid 200919 1167-1214. (https:// doi.org/10.1089/thy.2009.0110)

17 Haugen BR, Alexander EK, Bible KC, Doherty GM, Mandel SJ, Nikiforov YE, Pacini F, Randolph GW, Sawka AM, Schlumberger M, et al. 2015 American Thyroid Association management guidelines for adult patients with thyroid nodules and differentiated thyroid cancer: the American Thyroid Association Guidelines Task Force on Thyroid Nodules and Differentiated Thyroid Cancer. Thyroid 201626 1-133. (https://doi.org/10.1089/thy.2015.0020)

18 Park S, Kim WG, Han M, Jeon MJ, Kwon H, Kim M, Sung TY, Kim TY, Kim WB, Hong SJ, et al. Thyrotropin suppressive therapy for low-risk small thyroid cancer: a propensity score-matched cohort study. Thyroid 201727 1164-1170. (https://doi.org/10.1089/thy.2017.0177)

19 Kanis JA, Borgstrom F, De Laet C, Johansson H, Johnell O, Jonsson B, Oden A, Zethraeus N, Pfleger B \& Khaltaev N. Assessment of fracture risk. Osteoporosis International 200516 581-589. (https://doi. org/10.1007/s00198-004-1780-5)

20 Kanis JA, Harvey NC, McCloskey E, Bruyere O, Veronese N, Lorentzon M, Cooper C, Rizzoli R, Adib G, Al-Daghri N, et al. Algorithm for the management of patients at low, high and very high risk of osteoporotic fractures. Osteoporosis International 202031 1-12. (https://doi.org/10.1007/s00198-019-05176-3)

21 Miller PD, Siris ES, Barrett-Connor E, Faulkner KG, Wehren LE, Abbott TA, Chen YT, Berger ML, Santora AC \& Sherwood LM. Prediction of fracture risk in postmenopausal white women with peripheral bone densitometry: evidence from the National Osteoporosis Risk Assessment. Journal of Bone and Mineral Research 200217 2222-2230. (https://doi.org/10.1359/jbmr.2002.17.12.2222)

22 Ross DS, Neer RM, Ridgway EC \& Daniels GH. Subclinical hyperthyroidism and reduced bone density as a possible result of prolonged suppression of the pituitary-thyroid axis with L-thyroxine. American Journal of Medicine 198782 1167-1170. (https://doi. org/10.1016/0002-9343(87)90219-1) 
23 Marcocci C, Golia F, Bruno-Bossio G, Vignali E \& Pinchera A. Carefully monitored levothyroxine suppressive therapy is not associated with bone loss in premenopausal women. Journal of Clinical Endocrinology and Metabolism 199478 818-823. (https://doi. org/10.1210/jcem.78.4.8157704)

24 Sugitani I \& Fujimoto Y. Effect of postoperative thyrotropin suppressive therapy on bone mineral density in patients with papillary thyroid carcinoma: a prospective controlled study. Surgery 2011150 1250-1257. (https://doi.org/10.1016/j.surg.2011.09.013)

25 Marcocci C, Golia F, Vignali E \& Pinchera A. Skeletal integrity in men chronically treated with suppressive doses of L-thyroxine. Journal of Bone and Mineral Research 199712 72-77. (https://doi.org/10.1359/ jbmr.1997.12.1.72)

26 Faber J \& Galloe AM. Changes in bone mass during prolonged subclinical hyperthyroidism due to L-thyroxine treatment: a meta-analysis. European Journal of Endocrinology 1994130 350-356. (https://doi.org/10.1530/eje.0.1300350)

27 Heemstra KA, Hamdy NAT, Romijn JA \& Smit JWA. The effects of thyrotropin-suppressive therapy on bone metabolism in patients with well-differentiated thyroid carcinoma. Thyroid 200616 583-591. (https://doi.org/10.1089/thy.2006.16.583)

28 Papaleontiou M, Hawley ST \& Haymart MR. Effect of thyrotropin suppression therapy on bone in thyroid cancer patients. Oncologist 201621 165-171. (https://doi.org/10.1634/theoncologist.2015-0179)

29 Yoon BH, Lee Y, Oh HJ, Kim SH \& Lee YK. Influence of thyroidstimulating hormone suppression therapy on bone mineral density in patients with differentiated thyroid cancer: a meta-analysis. Journal of Bone Metabolism 201926 51-60. (https://doi.org/10.11005/ jbm.2019.26.1.51)

30 Wang MY, Han ZQ, Gong XW, Li Q \& Ma J. TSH-suppressive therapy can reduce bone mineral density in patients with differentiated thyroid carcinoma: a meta-analysis. European Review for Medical and Pharmacological Sciences 202024 922-929. (https://doi.org/10.26355/ eurrev_202001_20077)

31 Jodar E, Martinez-Diaz-Guerra G, Azriel S \& Hawkins F. Bone mineral density in male patients with L-thyroxine suppressive therapy and Graves disease. Calcified Tissue International 200169 84-87. (https:// doi.org/10.1007/s002230020041)

32 Schneider DL, Barrett-Connor EL \& Morton DJ. Thyroid hormone use and bone mineral density in elderly women. Effects of estrogen. JAMA 1994271 1245-1249. (https://doi.org/10.1001/ jama.1994.03510400031027)

33 Wang LY, Smith AW, Palmer FL, Tuttle RM, Mahrous A, Nixon IJ, Patel SG, Ganly I, Fagin JA \& Boucai L. Thyrotropin suppression increases the risk of osteoporosis without decreasing recurrence in ATA low- and intermediate-risk patients with differentiated thyroid carcinoma. Thyroid 201525 300-307. (https://doi.org/10.1089/ thy.2014.0287)

34 Flynn RW, Bonellie SR, Jung RT, MacDonald TM, Morris AD \& Leese GP. Serum thyroid-stimulating hormone concentration and morbidity from cardiovascular disease and fractures in patients on long-term thyroxine therapy. Journal of Clinical Endocrinology and Metabolism 201095 186-193. (https://doi.org/10.1210/jc.2009-1625)

35 Siris ES, Brenneman SK, Barrett-Connor E, Miller PD, Sajjan S, Berger ML \& Chen YT. The effect of age and bone mineral density on the absolute, excess, and relative risk of fracture in postmenopausal women aged 50-99: results from the National Osteoporosis Risk Assessment (NORA). Osteoporosis International 200617 565-574. (https://doi.org/10.1007/s00198-005-0027-4)

36 Seeman E \& Delmas PD. Bone quality - the material and structural basis of bone strength and fragility. New England Journal of Medicine 2006354 2250-2261. (https://doi.org/10.1056/NEJMra053077)

37 Legrand E, Audran M, Guggenbuhl P, Levasseur R, Chales G, Basle MF \& Chappard D. Trabecular bone microarchitecture is related to the number of risk factors and etiology in osteoporotic men.
Microscopy Research and Technique 2007 70 952-959. (https://doi org/10.1002/jemt.20501)

38 Godang K, Olarescu NC, Bollerslev J \& Heck A. Treatment of acromegaly increases BMD but reduces trabecular bone score: a longitudinal study. European Journal of Endocrinology 2016175 155-164. (https://doi.org/10.1530/EJE-16-0340)

39 Belaya ZE, Hans D, Rozhinskaya LY, Dragunova NV, Sasonova NI, Solodovnikov AG, Tsoriev TT, Dzeranova LK, Melnichenko GA \& Dedov II. The risk factors for fractures and trabecular bone-score value in patients with endogenous Cushing's syndrome. Archives of Osteoporosis 201510 44. (https://doi.org/10.1007/s11657-015-0244-1)

40 Eller-Vainicher C, Filopanti M, Palmieri S, Ulivieri FM, Morelli V, Zhukouskaya VV, Cairoli E, Pino R, Naccarato A, Verga U, et al. Bone quality, as measured by trabecular bone score, in patients with primary hyperparathyroidism. European Journal of Endocrinology 2013 169 155-162. (https://doi.org/10.1530/EJE-13-0305)

41 Van Staa TP, Laan RF, Barton IP, Cohen S, Reid DM \& Cooper C. Bone density threshold and other predictors of vertebral fracture in patients receiving oral glucocorticoid therapy. Arthritis and Rheumatism 200348 3224-3229. (https://doi.org/10.1002/art.11283)

42 Martineau P, Silva BC \& Leslie WD. Utility of trabecular bone score in the evaluation of osteoporosis. Current Opinion in Endocrinology, Diabetes, and Obesity 201724 402-410. (https://doi.org/10.1097/ MED.0000000000000365)

43 Harvey NC, Gluer CC, Binkley N, McCloskey EV, Brandi ML, Cooper C, Kendler D, Lamy O, Laslop A, Camargos BM, et al. Trabecular bone score (TBS) as a new complementary approach for osteoporosis evaluation in clinical practice. Bone 201578 216-224. (https://doi.org/10.1016/j.bone.2015.05.016)

44 Hwangbo Y, Kim JH, Kim SW, Park YJ, Park DJ, Kim SY, Shin CS \& Cho NH. High-normal free thyroxine levels are associated with low trabecular bone scores in euthyroid postmenopausal women. Osteoporosis International 201627 457-462. (https://doi.org/10.1007/ s00198-015-3270-3)

45 Kuzma M, Vanuga P, Binkley N, Sagova I, Pavai D, Blazicek P, Kuzmova Z, Jackuliak P, Vanuga A, Killinger Z, et al. High serum fractalkine is associated with lower trabecular bone score in premenopausal women with Graves' disease. Hormone and Metabolic Research 201850 609-614. (https://doi.org/10.1055/a-0633-2814)

46 De Mingo Dominguez ML, Guadalix Iglesias S, Martin-Arriscado Arroba C, López Alvarez B, Martínez Diaz-Guerra G, MartinezPueyo JI, Ferrero Herrero E \& Hawkins Carranza F. Low trabecular bone score in postmenopausal women with differentiated thyroid carcinoma after long-term TSH suppressive therapy. Endocrine 2018 62 166-173. (https://doi.org/10.1007/s12020-018-1671-8)

47 Moon JH, Kim KM, Oh TJ, Choi SH, Lim S, Park YJ, Park DJ \& Jang HC. The effect of TSH suppression on vertebral trabecular bone scores in patients with differentiated thyroid carcinoma. Journal of Clinical Endocrinology and Metabolism 2017102 78-85. (https://doi. org/10.1210/jc.2016-2740)

48 Cheung AM, Adachi JD, Hanley DA, Kendler DL, Davison KS, Josse R, Brown JP, Ste-Marie LG, Kremer R, Erlandson MC, et al. Highresolution peripheral quantitative computed tomography for the assessment of bone strength and structure: a review by the Canadian Bone Strength Working Group. Current Osteoporosis Reports 201311 136-146. (https://doi.org/10.1007/s11914-013-0140-9)

49 Ma J, Zhao J, He W, Kuang M, Chen H, Zhang L, Sun L, Cui Y, Ma X \& Wang Y. Review of high-resolution peripheral quantitative computed tomography for the assessment of bone microstructure and strength. Sheng Wu Yi Xue Gong Cheng Xue Za Zhi 201835 468-474. (https://doi.org/10.7507/1001-5515.201707068)

50 Tournis S, Antoniou JD, Liakou CG, Christodoulou J, Papakitsou E, Galanos A, Makris K, Marketos H, Nikopoulou S, Tzavara I, et al. Volumetric bone mineral density and bone geometry assessed by peripheral quantitative computed tomography in women with https://ec.bioscientifica.com https://doi.org/10.1530/EC-20-0167 (c) 2020 The authors Published by Bioscientifica Ltd

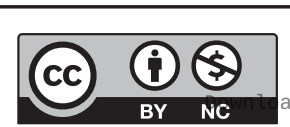

This work is licensed under a Creative Commons Attribution-NonCommercial 4.0 International License. ded from Bioscientifica.com at 04/26/2023 01:59:03PM 
differentiated thyroid cancer under TSH suppression. Clinical Endocrinology 201582 197-204. (https://doi.org/10.1111/cen.12560)

51 Kim K, Kim IJ, Pak K, Kim SJ, Shin S, Kim BH, Kim SS, Lee BJ \& Jeon YK. Evaluation of bone mineral density using DXA and CQCT in postmenopausal patients under thyrotropin suppressive therapy. Journal of Clinical Endocrinology and Metabolism 2018103 4232-4240. (https://doi.org/10.1210/jc.2017-02704)

52 Center JR, Nguyen TV, Schneider D, Sambrook PN \& Eisman JA. Mortality after all major types of osteoporotic fracture in men and women: an observational study. Lancet 1999353 878-882. (https:// doi.org/10.1016/S0140-6736(98)09075-8)

53 Cummings SR, Nevitt MC, Browner WS, Stone K, Fox KM, Ensrud KE, Cauley J, Black D \& Vogt TM. Risk factors for hip fracture in white women. Study of Osteoporotic Fractures Research Group. New England Journal of Medicine 1995332 767-773. (https://doi. org/10.1056/NEJM199503233321202)

54 Garin MC, Arnold AM, Lee JS, Robbins J \& Cappola AR. Subclinical thyroid dysfunction and hip fracture and bone mineral density in older adults: the cardiovascular health study. Journal of Clinical Endocrinology and Metabolism 201499 2657-2664. (https://doi. org/10.1210/jc.2014-1051)

55 Murphy E, Gluer CC, Reid DM, Felsenberg D, Roux C, Eastell R \& Williams GR. Thyroid function within the upper normal range is associated with reduced bone mineral density and an increased risk of nonvertebral fractures in healthy euthyroid postmenopausal women. Journal of Clinical Endocrinology and Metabolism 201095 3173-3181. (https://doi.org/10.1210/jc.2009-2630)

56 Wirth CD, Blum MR, da Costa BR, Baumgartner C, Collet TH, Medici M, Peeters RP, Aujesky D, Bauer DC \& Rodondi N. Subclinical thyroid dysfunction and the risk for fractures: a systematic review and meta-analysis. Annals of Internal Medicine 2014161 189-199. (https://doi.org/10.7326/M14-0125)

57 Blum MR, Bauer DC, Collet TH, Fink HA, Cappola AR, da Costa BR, Wirth CD, Peeters RP, Asvold BO, den Elzen WPJ, et al. Subclinical thyroid dysfunction and fracture risk: a meta-analysis. JAMA 2015 313 2055-2065. (https://doi.org/10.1001/jama.2015.5161)

58 Leese GP, Jung RT, Guthrie C, Waugh N \& Browning MC. Morbidity in patients on L-thyroxine: a comparison of those with a normal TSH to those with a suppressed TSH. Clinical Endocrinology 199237 500-503. (https://doi.org/10.1111/j.1365-2265.1992.tb01480.x)

59 Solomon BL, Wartofsky L \& Burman KD. Prevalence of fractures in postmenopausal women with thyroid disease. Thyroid 19933 17-23. (https://doi.org/10.1089/thy.1993.3.17)

60 Nguyen TT, Heath H 3rd, Bryant SC, O'Fallon WM \& Melton LJ 3rd. Fractures after thyroidectomy in men: a population-based cohort study. Journal of Bone and Mineral Research 199712 1092-1099. (https://doi.org/10.1359/jbmr.1997.12.7.1092)

61 Melton LJ 3rd, Ardila E, Crowson CS, O'Fallon WM \& Khosla S. Fractures following thyroidectomy in women: a population-based cohort study. Bone 200027 695-700. (https://doi.org/10.1016/s87563282(00)00379-3)

62 Sheppard MC, Holder R \& Franklyn JA. Levothyroxine treatment and occurrence of fracture of the hip. Archives of Internal Medicine 2002 162 338-343. (https://doi.org/10.1001/archinte.162.3.338)

63 Turner MR, Camacho X, Fischer HD, Austin PC, Anderson GM, Rochon PA \& Lipscombe LL. Levothyroxine dose and risk of fractures in older adults: nested case-control study. BMJ $2011342 \mathrm{~d} 2238$. (https://doi.org/10.1136/bmj.d2238)

64 Ko YJ, Kim JY, Lee J, Song HJ, Kim JY, Choi NK \& Park BJ. Levothyroxine dose and fracture risk according to the osteoporosis status in elderly women. Journal of Preventive Medicine and Public Health 201447 36-46. (https://doi.org/10.3961/jpmph.2014.47.1.36)

65 Viniol A, Hickstein L, Walker J, Donner-Banzhoff N, Baum E \& Becker A. Influence of thyroid hormone therapy on the fracture rate - a claims data cohort study. Bone 201686 86-90. (https://doi. org/10.1016/j.bone.2016.03.002)
66 Hung CL, Yeh CC, Sung PS, Hung CJ, Muo CH, Sung FC, Jou IM \& Tsai KJ. Is partial or total thyroidectomy associated with risk of long-term osteoporosis: a nationwide population-based study. World Journal of Surgery 201842 2864-2871. (https://doi.org/10.1007/ s00268-018-4573-2)

67 Fujiyama K, Kiriyama T, Ito M, Kimura H, Ashizawa K, Tsuruta M, Nagayama Y, Villadolid MC, Yokoyama N \& Nagataki S. Suppressive doses of thyroxine do not accelerate age-related bone loss in late postmenopausal women. Thyroid 19955 13-17. (https://doi. org/10.1089/thy.1995.5.13)

68 Heijckmann AC, Huijberts MSP, Geusens P, de Vries J, Menheere PPCA \& Wolffenbuttel BHR. Hip bone mineral density, bone turnover and risk of fracture in patients on long-term suppressive L-thyroxine therapy for differentiated thyroid carcinoma. European Journal of Endocrinology 2005153 23-29. (https://doi. org/10.1530/eje.1.01933)

69 Reverter JL, Colome E, Holgado S, Aguilera E, Soldevila B, Mateo L \& Sanmarti A. Bone mineral density and bone fracture in male patients receiving long-term suppressive levothyroxine treatment for differentiated thyroid carcinoma. Endocrine 201037 467-472. (https://doi.org/10.1007/s12020-010-9339-z)

70 Vera L, Gay S, Campomenosi C, Paolino S, Pera G, Monti E, Mortara L, Seriolo B \& Giusti M. Ten-year estimated risk of bone fracture in women with differentiated thyroid cancer under TSHsuppressive levothyroxine therapy. Endokrynologia Polska 201667 350-358. (https://doi.org/10.5603/EP.a2016.0046)

71 Mazziotti G, Formenti AM, Frara S, Olivetti R, Banfi G, Memo M, Maroldi R, Giubbini R \& Giustina A. High prevalence of radiological vertebral fractures in women on thyroid-stimulating hormonesuppressive therapy for thyroid carcinoma. Journal of Clinical Endocrinology and Metabolism 2018103 956-964. (https://doi. org/10.1210/jc.2017-01986)

72 Lin SY, Lin CL, Chen HT \& Kao CH. Risk of osteoporosis in thyroid cancer patients using levothyroxine: a population-based study. Current Medical Research and Opinion 201834 805-812. (https://doi. org/10.1080/03007995.2017.1378174)

73 Shin DW, Suh B, Lim H, Yun JM, Song SO \& Park Y. J-shaped association between postoperative levothyroxine dosage and fracture risk in thyroid cancer patients: a retrospective cohort study. Journal of Bone and Mineral Research 201833 1037-1043. (https://doi.org/10.1002/jbmr.3407)

74 National Clinical Guideline Centre (UK). Osteoporosis: Fragility Fracture Risk: Osteoporosis: Assessing the Risk of Fragility Fracture (NICE Clinical Guidelines, No. 146). London, UK: Royal College of Physicians. (available at: https://www.ncbi.nlm.nih.gov/books/NBK115321)

75 Panico A, Lupoli GA, Fonderico F, Marciello F, Martinelli A, Assante R \& Lupoli G. Osteoporosis and thyrotropin-suppressive therapy: reduced effectiveness of alendronate. Thyroid 200919 437-442. (https://doi.org/10.1089/thy.2008.0428)

76 Sharma A, Einstein AJ, Vallakati A, Arbab-Zadeh A, Walker MD, Mukherjee D, Homel P, Borer JS \& Lichstein E. Risk of atrial fibrillation with use of oral and intravenous bisphosphonates. American Journal of Cardiology 2014113 1815-1821. (https://doi. org/10.1016/j.amjcard.2014.03.008)

77 Baliram R, Sun L, Cao J, Li J, Latif R, Huber AK, Yuen T, Blair HC, Zaidi M \& Davies TF. Hyperthyroid-associated osteoporosis is exacerbated by the loss of TSH signaling. Journal of Clinical Investigation 2012122 3737-3741. (https://doi.org/10.1172/JCI63948)

78 Sampath TK, Simic P, Sendak R, Draca N, Bowe AE, O'Brien S, Schiavi SC, McPherson JM \& Vukicevic S. Thyroid-stimulating hormone restores bone volume, microarchitecture, and strength in aged ovariectomized rats. Journal of Bone and Mineral Research 2007 22 849-859. (https://doi.org/10.1359/jbmr.070302)

79 Sun L, Vukicevic S, Baliram R, Yang G, Sendak R, McPherson J, Zhu LL, Iqbal J, Latif R, Natrajan A, et al. Intermittent recombinant TSH injections prevent ovariectomy-induced bone loss. PNAS 2008 105 4289-4294. (https://doi.org/10.1073/pnas.0712395105)

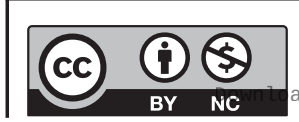

This work is licensed under a Creative Commons Attribution-NonCommercial 4.0 International License. ded from Bioscientifica.com at 04/26/2023 01:59:03PM 
80 van der Deure WM, Uitterlinden AG, Hofman A, Rivadeneira F, Pols HAP, Peeters RP \& Visser TJ. Effects of serum TSH and FT4 levels and the TSHR-Asp727Glu polymorphism on bone: the Rotterdam Study. Clinical Endocrinology 200868 175-181. (https://doi org/10.1111/j.1365-2265.2007.03016.x)

81 Vigone MC, Di Frenna M, Guizzardi F, Gelmini G, de Filippis T, Mora S, Caiulo S, Sonnino M, Bonomi M, Persani L, et al. Mild TSH resistance: clinical and hormonal features in childhood and adulthood. Clinical Endocrinology 201787 587-596. (https://doi. org/10.1111/cen.13387)

82 Kim TH, Joung JY, Kang M, Choi SK, Kim K, Jang JY, Cho YY, Min YK, Chung JH \& Kim SW. A modest protective effect of thyrotropin against bone loss is associated with plasma triiodothyronine levels. PLoS ONE 201510 e0145292. (https://doi.org/10.1371/journal. pone.0145292)

83 Mazziotti G, Sorvillo F, Piscopo M, Cioffi M, Pilla P, Biondi B, Iorio S, Giustina A, Amato G \& Carella C. Recombinant human TSH modulates in vivo C-telopeptides of type- 1 collagen and bone alkaline phosphatase, but not osteoprotegerin production in postmenopausal women monitored for differentiated thyroid carcinoma. Journal of Bone and Mineral Research 200520 480-486. (https://doi.org/10.1359/JBMR.041126)
84 Martini G, Gennari L, De Paola V, Pilli T, Salvadori S, Merlotti D, Valleggi F, Campagna S, Franci B, Avanzati A, et al. The effects of recombinant TSH on bone turnover markers and serum osteoprotegerin and RANKL levels. Thyroid 200818 455-460. (https://doi.org/10.1089/thy.2007.0166)

85 Karga H, Papaioannou G, Polymeris A, Papamichael K, Karpouza A, Samouilidou E \& Papaioannou P. The effects of recombinant human TSH on bone turnover in patients after thyroidectomy. Journal of Bone and Mineral Metabolism 201028 35-41. (https://doi. org/10.1007/s00774-009-0098-y)

86 Bassett JHD, Williams AJ, Murphy E, Boyde A, Howell PGT, Swinhoe R, Archanco M, Flamant F, Samarut J, Costagliola S, et al. A lack of thyroid hormones rather than excess thyrotropin causes abnormal skeletal development in hypothyroidism. Molecular Endocrinology 200822 501-512. (https://doi.org/10.1210/me.20070221)

87 van Vliet NA, Noordam R, van Klinken JB, Westendorp RG, Bassett JD, Williams GR \& van Heemst D. Thyroid stimulating hormone and bone mineral density: evidence from a two-sample Mendelian randomization study and a candidate gene association study. Journal of Bone and Mineral Research 201833 1318-1325. (https://doi.org/10.1002/jbmr.3426)

Received in final form 27 May 2020

Accepted 18 June 2020

Accepted Manuscript published online 19 June 2020
This work is licensed under a Creative Commons Attribution-NonCommercial 4.0 International License. ded from Bioscientifica.com at 04/26/2023 01:59:03PM 